\title{
Assessment of Surface Transportation Security Training Needs and Delivery Preferences
}

\author{
Karen W. Lowrie, Judy A. Shaw, Michael R. Greenberg \\ Center for Transportation Safety, Security and Risk \\ Rutgers University
}

\begin{abstract}
America's surface transportation system features long and inter-connected routes and open access to stations and vehicles, making the system vulnerable to terrorist attack. While a variety of security-related training products exist for the transportation sector, government and other reports have called for improvements in the transportation security training curriculum in terms of quality and consistency. At the same time, tight economic times have left few extra financial resources available for systems to deliver adequate training to employees. This study assessed the needs for additional security training through focus groups and interviews with representatives of major surface transportation stakeholders and agencies. Training content needs and the approaches that will most effectively implement training in the field are identified. The results are intended to inform those responsible for supporting, developing, or implementing security training about where gaps may exist and about which delivery mechanisms are preferred and most workable.
\end{abstract}

\section{Introduction and Background}

America's surface transportation system of roads, bridges, railroads, and subways and the buses, cars, and trains that travel on them feature long and inter-connected 
routes and open access to stations and vehicles. These attributes make the system very vulnerable to terrorist attack. Public transit systems that carry hundreds of thousands of people daily in crowded buses and railcars are particularly attractive targets for terrorists whose goal is to affect the greatest amount of people in a confined space. Recent intelligence obtained after the death of Osama Bin Laden indicates that plans to sabotage surface transportation systems were in development. "Implementing Recommendations of the 9/11 Commission Act of 2007," also called the " $9 / 11$ Act" declares that a training program should be developed to "prepare public transportation employees, including frontline employees, for potential security threats and conditions" (Library of Congress). More recently and more broadly, a quadrennial review by the Department of Homeland Security (DHS) identified training for major incidents and coordinating preparedness and responses as major objectives (2010).

While a variety of security-related training products exist for the transportation sector, a 2010 report by the Government Accountability Office (GAO) found that the mass transit training curriculum can be improved in terms of quality and consistency. At the same time, tight economic times have left few extra financial resources available for systems to deliver adequate training to employees (Waugh 2004; Meyer 2008).

The 9/11 Act outlines the learning objectives or program elements for frontline employee training, including (1) threat determination, (2) suspicious activity reporting, (3) passenger communication, and (4) appropriate response actions. The Act also recommends live situational training exercises as important elements. In light of the identified concerns and challenges of securing our nation's transit system, this study set out to gain an understanding of the needed content areas and delivery mechanisms that can best accomplish training objectives for transit employees and managers.

Outside of the federal government, experts and stakeholders also have noted the need for more effective transportation security to deal with the terrorism threats the United States faces in the early 21st century (AASHTO 2002; Fries et al. 2008; Helmick and Compton 2004; Johnston 2004; Meyer 2008; Mitchell et al. 2004). Because potential threats are present in train and bus stations, ports, platforms and waiting areas, and on surface and maritime vehicles, all surface transportation workers need some training in the recognition and assessment of potential hazards and dangerous activities, as well as response and notification protocols in the event of an incident or evacuation. 
There is little, if any, published literature that looks at security training needs for the transportation sector specifically. However, identification of training needs for any type of worker who could encounter dangerous chemical, biological, or radiological weapons or bombs was the subject of a 2002 conference sponsored by CDC and National Institutes of Occupational Safety and Health (NIOSH) and held at Johns Hopkins University. In a summary article, Mitchell et al. (2004) identify five key needs as training in the potential hazards involved: the individual worker's specific role in an emergency, incident command, activation of the emergency notification system, use of personal protective equipment (PPE), and safe evacuation of the workplace.

In the general training literature, there are numerous studies comparing the effectiveness of trainer attributes (Steiner et al. 1991) or of different training methods on skill retention and transfer of learning. Studies have shown that peer support in the training context resulted in greater improvement in skills (Martin 2010), and that supervisory support was not as influential (Van der Klink et al. 2001). An older study noted that traditional training methods may need to be adapted to work in a highly-unionized industrial setting (Young and Findlater 1972).

The promise of using computer-based learning formats is being explored, with the caveat that technology itself will not improve training outcomes without identification of the proper target audience and selection of the proper instructional strategies to meet objectives (Myers et al. 2008). Sitzman et al. (2009) add that in computer-based learning, prompting self-regulation (e.g., stop points with questions) resulted in stronger performance gains over time, especially for trainees who already have higher ability or higher self-efficacy. These results demonstrate prompting self-regulation improved performance over time, relative to the other conditions. Virtual teaming in training also was found to be effective in a study by Ahanchian and McCormick (2009), but also subject to the trainees' cultural predisposition to individualism (learning and doing things alone) vs. collectivism (learning and spending more time in groups). Gershon et al. (2010) found that a recently developed web-based simulation program was effective in training transit police officers in New York on how to recognize and respond to WMD attacks. However, Lammers et al. (2008) conclude that additional study is necessary to evaluate whether skills learned via simulation translate into real-world setting. 


\section{Call for a Needs Analysis}

The Obama administration has identified "understanding transportation security training programs and gaps" as one of 20 priorities to improve security (President's Office 2010). The Transportation Safety Administration (TSA) currently is preparing a matrix that lists available security training programs offered through and approved by federal agencies such as TSA, the Federal Emergency Management Agency (FEMA), and the U.S. Department of Transportation's Federal Transit Administration (FTA).

It is not the objective of this paper to identify all existing programs, but rather to assess the needs for additional security training or identify gaps, and to learn from people in the transportation sector about the most effectively-implemented training in the field. The results are intended to inform those responsible for supporting, developing, or implementing security training on where gaps may exist and what delivery mechanisms are preferred and most workable.

\section{Research Questions}

The following research questions guided the analysis:

- What are the content needs and gaps in security training and education for surface transportation?

- What are the preferred approaches for effective training delivery to key audiences?

\section{Methods}

The study took place in four phases during 2009 and 2010 and resulted in obtaining input from 70 transportation and transit industry stakeholders representing 45 different transportation or security organizations through interviews and focus group methods. (See reports from each phase of research: Kozub et al. 2009a; Kozub et al. 2009b; Shaw 2010; Shaw and Lowrie 2010).

The data collection consisted of four parts: two regional stakeholder focus groups, one held in metropolitan New York with 24 participants and one in Houston with 12 participants and two sets of telephone interviews, one conducted with 19 transportation stakeholders in California and another conducted with 15 representatives from union, trade, and training organizations. 
The focus group meetings lasted 4-5 hours, with participants broken into small groups of 5-8 people, each with a note-taker and facilitator from the research team. The three guiding questions for discussion were the following:

1. Who are the key audiences in need of security training?

2. What are the key content areas needed for security training?

3. What are the best and preferred delivery methods for training?

The interviews were conducted by phone with leaders and representatives of transportation organizations selected by consulted experts and also through a snowball sample from initial contacts. Interviewees were asked the same three questions as the focus groups, with prompts to guide discussion in the absence of the group prompts that would occur naturally in a focus group.

The surface transportation modes represented in the focus groups and interviews included city and regional public transit, intercity bus, rail, freight rail, ports, and highway, bridge, and tunnel agencies. Also, some city, county, and state public safety, homeland security, and emergency management personnel took part in the study (see Acknowledgments). Participant roles within the agencies and organizations were from either the training area, such as training managers, or the security/ safety area, such as directors of security operations.

\section{Findings}

The findings from the data collection are summarized and synthesized into two main categories: training needs and delivery methods. The findings are broken down by various training audiences in both sections rather than by mode, because interviews revealed that employees within each of the transportation modes have very similar training needs. Findings that apply generally to all types of employees/ audiences also are included.

\section{Security Training Content Needs}

\section{General Training Content Needs}

Participants recommended two key areas of content that are necessary for all types of employees and audiences, related to the broad areas of assessment and response. First is basic security awareness and risk assessment. In other words, there is a content gap related to training personnel to think analytically and assess what is suspicious and what is a true risk or emergency. Second, all employees of an agency or transportation network need to understand response protocols for 
managing security incidents in those first minutes before law enforcement or first responders arrive. A common example would be the need to coordinate an evacuation of a city bus or a train platform. A key to effective response is communicating within the chain of command-knowing when to call and whom to call to report an incident or concern, and also communicating with riders or the general public. Many participants in the study commented that a "systems perspective" is helpful in response training - that is, an awareness of the network of organizations and modes that need to work together and have roles to play in both prevention and response.

Improved assessment and response could be accomplished by cross-training exercises and drills that involve multiple agencies, such as those carried out to train response agencies within the Incident Command System. Transportation personnel need to be involved in these multi-agency regional training exercises to the greatest extent possible, since this sector is just as vulnerable to terror and other human crime or attacks as other sectors.

\section{By Audience}

In addition to the general needs that apply across the transportation sector, study participants were asked about training content needs for six different audiences: frontline employees and their supervisors, transportation managers and professionals, transportation security and police officers, customers, contractors, and emergency responders. This section includes descriptions of each audience type and summarizes the training gaps pertaining to each group that were identified in the study.

Frontline Employees. Frontline employees are those who interact with customers or are directly responsible for providing and maintaining service. Examples are bus and rail operators, train engineers, conductors, mechanics, station agents, track workers, cleaners, customer service agents, and all of their respective, immediate supervisors. Any type of employee, from a road crew to an operator, could be called upon to respond in an emergency, but there is a common perception across all groups that frontline transit workers are under-trained in preventive and responsive practices.

For frontline employees, the topics identified as "general needs" above are critical ones. Even though there is some existing training on behavioral recognition and reporting, respondents felt that this should be expanded. Frontline employees need training on observational skills related to how to identify suspicious activi- 
ties, surroundings, and packages. Training should focus on taking appropriate steps immediately, including how to communicate and report about those suspicions and incidents with awareness of the role of other emergency service providers.

In addition to these, the specific training needs identified for this audience related to:

- Evacuation and crowd control

- Emergency procedures for special populations (persons with disabilities, etc.)

- Protection of self and others

- Proper use of security equipment and technology for access control, alerts, and communication protocols

Because of their duties, some employees of different roles and modes may need specific training to better carry out their security-related responsibilities. The following are some examples:

- Station agents, conductors and bus operators who constantly interact with customers need more training on communicating with and managing those customers during an incident.

- First-line supervisors and managers need a higher level of training in overall incident management and the National Incident Management System to effectively carry out their responsibilities during an emergency.

- Vehicle, equipment, right-of-way, and facility maintenance and mechanical employees, including structural engineers, inspectors, and dedicated craft employees, need further training on sabotage and other attack tactics used against assets.

- Rail frontline employees need specific training for how to handle a crisis on an uncontrolled stretch of track or tunnel.

- Freight rail personnel need to know about the safety and security threats of carrying hazardous or dangerous cargo.

- School bus drivers in thousands of school districts across the country, carrying millions of children every day, get very little, if any, training about hazards and security.

There was clear concern that training for frontline personnel does not need be too in-depth or technical. The training also needs to be maintained and kept current with case studies, statistics, and references that are timely and relevant.

Finally, one of the trade group representatives in our study observed that supervisors and station managers (middle management) need to be included with front- 
line employees to break the "us vs. them" mentality and build a team approach. Focus group participants also felt that when frontline employees feel supported, it creates a positive climate of preparedness gives them confidence to act based on what they learn in training.

Professionals/Managers/Policy-Makers. Transportation professionals are mid- to high-level managers and executives in operations, planning, safety, security, maintenance, and other related fields. Our forum participants expressed a perception that the professional level does not have adequate training in security topics. Aside from the same basic security awareness training for frontline employees, this audience has special high-level training and education needs in the area of security risk assessment and management, vulnerability assessment, and planning for resiliency.

Regarding risk assessment and management, policy-makers need to understand likelihoods and consequences of various incidents in a transportation environment. They also need to understand how to apply risk assessment thinking and simulation results to decisions about cost-effective and proper mitigation and response solutions. Additional training in "security risk communication" also was identified-understanding how the public perceives risks, responds to risks, and how to properly communicate risks. In the area of vulnerability, professionals need training on how to recognize vulnerability within systems (i.e., places with easy access or more exposure to threats) and how to minimize vulnerability through both infrastructure design and hardening of current assets. This means ensuring that security considerations are included in all phases of planning, from initial investment through system operation and maintenance.

Study participants also felt that transit managers need to plan for redundancy and continuity of operations, such as resiliency planning, i.e., how to shift modes or routes to handle passengers in an emergency. Learning from past incidents is a good way to do this, but there is a gap in knowledge about previous incidents and applying lessons learned and best practices to improvements in resiliency.

One focus group thought that transportation professionals need to understand more clearly the difference between safety and security and the tension between them; a door could be secure from unwanted entry but may be less safe in terms of easy exit for fire safety. This group felt that safety issues are always paramount, while security issues are more likely to be pushed aside. 
Another idea was to explore the issues and opportunities related to the creation and delivery of professional development courses for existing managers within the industry. A culture of professionalism might then evolve and drive the demand for these courses. Also, more certificate and degree programs for undergraduate and graduate level students will help to bring highly-trained professionals into the industry but who may expect continuing education opportunities.

Transportation Security and Police. Transportation security and police officers have the strongest direct connection with security awareness and response, since it is their specific job responsibility. Many are graduates of criminal justice degree programs and most undergo police academy training programs, but few have had specific counter-terrorism training related to transportation operations.

The primary needs of this group were classified into two areas. The first focuses on the need for a transportation-oriented police training program that would build a baseline level of commonality and credibility thereby reducing disparities between agency programs. This program should include:

- Overview of transportations systems and operations

- In-depth study of the security issues that impact transportation systems

- Explanation of security related vulnerabilities within transportation systems

- Review of hardening tactics employed by transportation security forces

- Explanation of legal issues regarding interacting with transportation customers

The second training need for transportation police is some form of continuing education. The current method of sharing information, best practices, and case histories is through industry association meetings. Police officers and security personnel require more structured educational programs to address both modalspecific and multimodal issues. As with the initial training program for new officers, the continuing education programs need to be offered to all modes and systems of all sizes to ensure industry-wide inclusion.

Customers. Customers of all modes also were seen as a viable group to receive security training at varying levels. Customers range from individuals using the services of intercity rail or bus to the companies and corporations that are served by the freight railroads.

Regarding individual customers, the needs focus on information sharing in multiple forms. These include prevention-based public awareness messages and 
incident-based information about service disruptions, detours, and other timesensitive issues. The California interviewees noted that in communicating with the public, transit organizations need to strike the right balance between awareness and anxiety, so they should develop approaches that foster awareness but do not alarm the passengers.

Additional training beyond a public message displayed on signs could include sharing information about how to distinguish what is dangerous from what is not. Text messages can inform passengers about recommended actions in the event of an emergency. In a few instances, agencies provide training for riders such as voluntary sessions to train customers to aid in evacuations and emergency preparedness and response.

Customers of the freight rail lines are primarily the companies that use the rail lines for shipping their goods. Training would cover their responsibilities for security measures within their facilities, including the railcars stationed on their property for loading, unloading, or storage. It was noted, for example, that the freight companies need to communicate with shippers, clients, and first responders along the route to ensure consistency in handling emergencies along the whole chain of shipping from beginning to end. Another "outside the box" method of increasing security is for freight railroad companies to use rail enthusiasts as resources to look for suspicious activity as they are watching or photographing trains.

Contractors. Contractors, particularly those who provide services on the vehicles, facilities, right-of-way, and service routes of the transportation agencies and companies, also are considered part of the requisite audience for security training programs. Contractors also include food service and gift establishments in rail stations. Given their physical presence within any given operation, training programs that exclude this audience in content or delivery would be insufficient, and the lack of training would contribute to potential security vulnerabilities.

The training content needs for this group will not be much different from that of the frontline employees in terms of emphasis on reporting suspicious and dangerous activities, but would vary in priority based on the contractor or vendor's proximity and access to critical infrastructure and operations (for maintenance workers) and to public areas (for food and other commercial vendors).

Some of our interviewees suggested that contractors or vendors could be included in both awareness and response training drills, if possible. Training could be provided as a perk for those with transit contracts or offered in exchange for other 
services. Short of actual training, another option is to instruct frontline employees and the transit police to use informal approaches to advise contractors on the practices of reporting suspicious behavior.

Emergency Responders. First responders play an essential role in assisting a transportation system in hardening its security measures. Whether local, county, or state police officers are patrolling areas that include transportation assets or operations, or fire and EMS personnel are responding to alarms, overall knowledge of specific operations, hazards, and vulnerabilities is critical to safe and effective response to incidents on or near transportation systems.

Study participants felt that emergency responders could be trained to know more about interfacing with transportation systems. In addition, middle- to high-ranking managers from both transportation systems and emergency services would benefit directly from an integrated approach to incident management training as it relates to the complicated transportation sector. The National Emergency Response and Rescue Training Center (NERRTC) of the Texas Engineering Extension Service (TEEX) is an example of a program that integrates all groups and sectors into intensive emergency preparedness and response training (see http://teex.com/ner$\mathrm{rtc} /$ ). Many states have strong programs for training emergency responders, but there is little coordination between emergency responders and transit operators. Study participants noted that such programs need to be integrated into a program that also trains transit operators, transit administration/professionals, emergency responders, and police and fire services.

Table 1 summarizes the content needs identified for the different audience types.

\section{Preferred Delivery Methods for Security Training}

This section summarizes participants' preferences for delivery of training for different audiences (format, length, location), and also includes their suggestions for approaches to make delivery of training more feasible and convenient.

\section{Instructor-Led Classroom Training}

The small group classroom environment generally is seen as the most effective format for learning. It allows for multi-media presentation and gives the participants opportunity for interaction with their colleagues. One interviewee expressed it this way: "Experienced students will provide examples and scenarios, and there is synergy among the students." The classroom training format also allows the instructor to gauge the effectiveness of the training, adjust the approach if it is not working well, and maximize learning. 


\section{Table 1. Summary of Needs by Audience}

\begin{tabular}{|c|c|}
\hline Audience & Content Needs \\
\hline Frontline & $\begin{array}{l}\text { - Situational assessment of threats and incidents } \\
\text { - Observational skills and reporting dangerous substances, suspicious pack- } \\
\text { ages, and situations } \\
\text { - Appropriately reacting to all threats } \\
\text { - Crew and passenger communication and coordination } \\
\text { - Appropriate responses to defend or protect oneself and customers } \\
\text { - Evacuation procedures for passengers and employees, including individu- } \\
\text { als with disabilities and the elderly } \\
\text { - Proper use of security equipment or technology }\end{array}$ \\
\hline $\begin{array}{l}\text { Transportation } \\
\text { Professionals }\end{array}$ & $\begin{array}{l}\text { - Risk assessment and management } \\
\text { - Applying risk and vulnerability concepts to transportation } \\
\text { - Security risk-based decision making } \\
\text { - Security risk communication } \\
\text { - Redundancy and resiliency planning } \\
\text { - Integrated incident management with field personnel }\end{array}$ \\
\hline $\begin{array}{l}\text { Transportation } \\
\text { Security and } \\
\text { Police Officers }\end{array}$ & $\begin{array}{l}\text { - Study of security issues impacting transportation systems } \\
\text { - Explanation of security related vulnerabilities within transportation } \\
\text { systems } \\
\text { - Review of hardening tactics employed by transportation police and } \\
\text { security forces } \\
\text { - Continuing education and reinforcement of "reality" of a terrorist incident }\end{array}$ \\
\hline Customers & $\begin{array}{l}\text { - Informational programs such as "If you see something, say something" } \\
\text { - Knowledge of emergency procedures } \\
\text { - Awareness of security measures relative to shipments and storage for } \\
\text { users of freight rail }\end{array}$ \\
\hline $\begin{array}{l}\text { Contractors and } \\
\text { Vendors }\end{array}$ & $\begin{array}{l}\text { - Similar to frontline employee awareness training } \\
\text { - Reporting suspicious activity }\end{array}$ \\
\hline $\begin{array}{l}\text { Emergency } \\
\text { Responders }\end{array}$ & $\begin{array}{l}\text { - Transportation system operations, hazards, and vulnerabilities } \\
\text { - Integrated communications and response practices and procedures } \\
\text { - Integrated incident management }\end{array}$ \\
\hline
\end{tabular}

Participants suggested that Subject Matter Experts (SMEs) should lead training to deliver knowledge and provide immediate feedback. When the leader is not an SME, the best format is a facilitated discussion, where the leader engages the expertise of those in the room to achieve the training goals. Respondents preferred courses that incorporate video and also include opportunities for the students to apply their skills in role-playing, with feedback from the instructor and peers, for better integration of the learning goals. 
To be more practical and cost-effective for agencies, new classroom trainings should be designed so that they are flexible in time duration, for example, 10-minute modules that can be integrated into other meetings or trainings. The preferred length for training in a particular topic is $2-3$ hours at a time.

\section{Scenario-Based Training}

For all subject areas and modes, study participants called for courses that are realistic and relevant. The effective use of scenario-based training exercises or drills, both tabletop and live or full-scale, was identified as a critical component to security training programs. For frontline employees, in particular, there was general agreement in favor of hands-on training and problem-solving for maximized integration of learning goals. When teams of employees must handle responses together across job functions, participants develop a sense of teamwork that is seen as a key element of effective on-scene management. Agencies can then evaluate those response actions and correct policies, procedures, or practices that are found to be counterproductive to effective response.

Live drills, however, are both expensive and time-intensive, involving elaborate staging, preparation, and debriefing. Because of the cost and difficulty of doing this for large groups, showing video of "live" scenarios is a viable alternative.

\section{Online and Computer-Based Training}

Reactions to computer-based training (CBT) were varied; some liked it for its flexibility, time savings, and consistency in content, while others felt it was not useful because it does not have the same verifiability of delivery that a classroom has, i.e., without an instructor present, there is no confidence that the desired learning goals have been accomplished. Self-paced learning can be set up to include stop points and pre- and post-tests, but many felt that CBT cannot replicate the human interaction of a classroom. Another downside is that if done individually, it can foster the problem of "silos" - the lack of understanding of other perspectives and roles. Other practical drawbacks to CBT include lack of access to enough computers to train thousands of employees within some systems or lack of familiarity with computers among employees.

Many suggested posting trainings online so they could be accessed easily from multiple or remote locations. Refreshers could be provided this way and could be particularly useful for managers. Union respondents saw the value in the self-paced format but also pointed out that it is successful only for highly-motivated employees with good work habits and educational skills. 


\section{Interactive Videos and Games}

Interactive videos and games feature the ability to actively participate in a simulated scenario that takes place in a virtual environment. When the trainee makes the wrong decision, the game or program will loop back and allow for correction. Some participants commented about these formats, agreeing that they can work well if interesting and fun, i.e., not watching words on a screen and scrolling through them to get to the end. The trainers in the study noted that they appreciate games where there is a real consequence if a mistake is made.

There are also some of the same drawbacks as seen with CBT-not all work environments have computers and not all workers are skilled in using computers. This is particularly true in smaller or rural operations and among older or immigrant transit worker populations in urban areas for whom English is a second language. Also, if a scenario is generic and not tailored to local circumstances, it is not familiar and thus less "real" to the participants. For games to be meaningful, it is ideal if the local host has the ability to integrate local context and procedures into the game format.

\section{Webinars}

Internet-based webinars and teleconferences are gaining popularity. When transit organizations have financial constraints or are challenged to take staff out of their shifts to take training, webinars allow them to participate directly from their work sites. These formats still allow for the give-and-take and peer-to-peer learning found in a classroom setting, and there is still a desire for this to be balanced with some face-to-face training, which tends to ensure engagement.

\section{Cross-Training}

As mentioned in the content section above, a common theme that emerged from this study was the importance of having mid-level managers, frontline employees, and police personnel from the same agency together in training sessions. People with different roles and representing different modes need opportunities to learn from each other and to become comfortable with procedures and protocols.

Cross-training also means conducting some sessions, where appropriate, with an inter-agency audience. The goals for such training are that participants have a common approach, know one another and their organizations, and know how to support each other in the event of a crisis. Participants noted a need for sponsorship and coordination by a "surrogate," e.g., DHS or universities. 


\section{Refresher Courses}

Many participants noted that although employees are generally trained at the time of hiring, many operations have no formal refreshers. Courses should be offered in the form of annual refresher courses on important security topics, with updated information and new technologies incorporated. These refreshers on security topics could be offered in conjunction with other regular meetings or required tests or re-certifications. For example, in California, bus operators are required to have an annual Verification of Transit Training (VTT), which offers a universal opportunity for all operators to be trained on security issues. Industry association interviewees point out that annual meetings are good places to co-locate training to save time and reduce costs.

One method of ongoing education is the posting of safety messages in locations where people will read them. Bulletins can be distributed, or pocket guides can be carried by employees. Study participants also suggested that agencies should perform "spot checks." For example, one agency uses the "red-card" system where a manager walks around randomly and gives out a red card to an employee with a scenario and asks what they would do. One interviewee observed: "Skills and knowledge have a shelf life-if not practiced within 90 days, they've probably forgotten a good amount."

\section{Summary and Recommendations}

This section begins with a consolidation of the concerns that emerged across all of the groups regarding the major challenges faced in delivering transportation security training. Table 2 lists these challenges and corresponding suggestions for overcoming these challenges based on input from study participants. Then, the major findings collected from the needs analysis study are presented. These findings, with associated recommendations that flowed directly from the identification of needs, relate to the two main research questions concerning training topic or content needs and training delivery format. 


\section{Table 2. Training Delivery Challenges and Recommendations}

\begin{tabular}{|c|c|}
\hline Delivery Challenge & Recommendation \\
\hline $\begin{array}{l}\text { Expensive for transit agencies } \\
\text { to pay operators for classroom } \\
\text { training time (overtime or backfill } \\
\text { pay required) }\end{array}$ & $\begin{array}{l}\text { - Incorporate into regular meetings or other training } \\
\text { - Offer shorter training and CBT, where possible } \\
\text { - Apply for federal dollars to support training }\end{array}$ \\
\hline High turnover of employees & $\begin{array}{l}\text { - Incorporate security elements into new employee training } \\
\text { - Introduce more refreshers } \\
\text { - Add to other required certifications (e.g., CDL or VTT) }\end{array}$ \\
\hline Lack of "mandate" & - Create certification or "professional development" culture \\
\hline $\begin{array}{l}\text { Lack of mobility for managers or } \\
\text { scattered employees to attend } \\
\text { training (cutbacks on travel) }\end{array}$ & - More online or remote delivery options, webinars, DVDs \\
\hline Lack of computer skills & $\begin{array}{l}\text { - Keep computerized training simple and use it in combina- } \\
\text { tion with face-to-face training }\end{array}$ \\
\hline $\begin{array}{l}\text { Complexity of coordination } \\
\text { among transit agencies, local } \\
\text { police, and other responders }\end{array}$ & - Establish interagency training sessions \\
\hline
\end{tabular}

\section{Key Content Findings}

- The primary training content needs are behavioral recognition and reporting (prevention) and security incident response.

- Frontline transit employees need more initial security training and periodic refreshers.

- There is a need to develop modal-specific standards and learning objectives for security oriented training and education.

- Courses need to provide a better understanding of the "big picture" and systems perspective for all audiences.

- Consistent information about security protocols should filter from management to employees.

- Frontline employees and police need a clear consensus definition of what is "suspicious" and skills to assess risks and situations.

- Upper-level management needs to maintain vigilance that a terrorist attack could occur and keep the agency in readiness mode.

- Different agencies sponsoring training and the organizations that provide it should improve consistency and coordination between course content.

- Analysis of reported information (e.g., suspicious activity reporting) needs to continually inform and revise training. 
- Transit employees and emergency responders need integrated response training.

- Customers need to recognize and report unusual behavior.

- A baseline or benchmark standard of minimum training based on core objectives and competencies for each audience should be created and communicated by the federal government.

\section{Key Delivery Findings}

- Classroom training is preferred, but alternatives may train more employees more efficiently.

- Wherever possible, training should be scenario-based and focused on problem-solving.

- There is a need for refresher trainings to provide audiences with updated information and technologies.

- To increase convenience and reduce costs, training could be added either before or after existing trade association meetings or other required meetings.

- There is a need for cross-training formats to ensure that all levels of employees are responding in concert when there is an emergency.

- Interactive videos are gaining favor as effective training delivery systems.

- Interactive game formats can be flexible and cost-effective but need to be developed with feedback loops that ensure the information is learned.

\section{Future Directions}

Because there is no "one size fits all" product that will work to train all surface transportation employees, the emphasis in all modes was on a comprehensive or "campaign" approach to training packages. This would allow agency managers the opportunity to pick the best approach for their employees based upon responsibilities, availability, geographic and time constraints, and learning styles. For example, a course to teach awareness skills could include instructor-led modules, on-line elements, a computer-based interactive $C D$, videos, and printed materials to support training efforts in a way that meets the agency's needs. Because of the continuing and worsening logistical difficulties to using work time to do training, approaches that minimize training time and maximize scenario-based problemsolving opportunities are highly recommended.

Finally, two recurrent and overarching questions arose in our groups and interviews-one concerning the mandate for more security training and the other concerning how to evaluate its effectiveness. A concern was voiced that if sufficient incentives are not available to promote security-related training and if it is purely 
voluntary for surface transportation organizations to implement it, the nation will not meet the goal of providing the public with maximum safety. One union representative interviewee recommended that TSA mandate security courses and set certain security standards for transportation organizations. Yet, at the same time, the trade groups noted that they worry about unfunded mandates; if training is to be mandatory, a funding stream would be necessary. If it is recommended but not mandatory, support for agencies to deliver the training would foster greater and quicker spread of the training across the industry.

It is important for policy-makers to continually reevaluate whether security training is meeting its goals of broadly preparing employees of the transportation sector with skills to prevent and mitigate the impacts of hazards. This includes periodically assessing the training landscape in terms of the content that is provided, the quality of that content, and the effectiveness of delivery methods. For example, to detect whether training results in changed behaviors, it may be important to develop measures that present trainees with evaluation questions that consist of job-related scenarios, or even to measure direct changes in job performance at some period after training occurs (Ostroff 1991). A key issue for the future will be how to realistically implement adequate training according to these identified needs, given current fiscal constraints. More research and experimentation into effective ways to train with limited budget and time resources is worthy of attention.

If the federal government is to heed the call to keep our roads, railways, bridges, waterways, and tunnels safe, there will need to be support for training itself and also for research that can build the foundation for state-of-the-art training courses and innovative delivery mechanisms. Continued scientific inquiry into questions of effectiveness in meeting security goals is essential. Addressing the security training gaps identified in this study and providing delivery methods and formats that meet today's organizational contexts and practical realities will result in enhanced protection against the threats that face our nation's transportation systems.

\section{Acknowledgments}

This research was supported by the U.S. Department of Homeland Security, Science and Technology Directorate, Office of University Programs, under Grant Award Number 2008-ST-061-TS007. We acknowledge the assistance of Chris Kozub, Renee Haider, and Jon Carnegie in instigating the project and facilitating focus groups, and we thank Georgia Harrigan and Michael Tobia of DHS for supporting this work. 
We also acknowledge the assistance of National Transportation Security Center of Excellence partner institutions Texas Southern University and Mineta Transportation Institute at San Jose State University. The views and conclusions contained in this document are those of the authors and should not be interpreted as necessarily representing the official policies, either expressed or implied, of the U.S. Department of Homeland Security or the individuals mentioned above.

Representatives from the following agencies and organizations participated in this study: Adirondack Trailways, Association of American Railroads, American Association of State and Highway Transportation Officials, American Federal of State, County and Municipal Employees, American Public Transportation Association, Amtrak, Association of American Railroads, Bay Area Rapid Transit, Black River \& Western Railroad, California Department of Transportation (Caltrans), California Emergency Management Agency, CAT Eyes, Coach USA, Community Transportation Association of America, Conrail, Contra Costa County Transportation Authority, Foothill Transit System, Golden Gate Transit, Greyhound, Gulf Coast Freight Rail District, Houston City Mayor's Office, Houston METRO, Houston Transtar, International Chemical Workers Union, Los Angeles County Transportation Authority, Metropolitan Transportation Authority (MTA), MTA Long Island Railroad, MTA Metro-North Railroad, MTA NYC Transit, Morristown \& Erie Railway Co., National Transit Institute, New Jersey Turnpike Authority, NY \& Atlantic Railway, New York City Office of Emergency Management, Passenger Vessel Association, PATH, Sacramento Police Department, San Diego Metropolitan Transit System, Santa Clara Valley Transportation Authority, South Tahoe Area Transit Authority, Southeastern PA Transportation Authority (SEPTA), Texas Department of Transportation, Transport Workers Union of America, United Transportation Union, Alan M. Voorhees Transportation Center, and Rutgers University.

\section{References}

Ahanchian, M., and J. McCormick. 2009. Culture and the processes of virtual teaming for training. Journal of Computer Assisted Learning 25: 386-396.

AASHTO. State DOT's Transportation Security Training Needs. 2002. TransTech Management, Inc. www.transportation.org/sites/security/docs/Draft_Security_Training_Needs.pdf. 
Fries, R., M. Chowdhury, and J. Brummond. 2008. Need for Surface Transportation Infrastructure Security, in Transportation Infrastructure Security Utilizing Intelligent Transportation Systems. Hoboken, NJ: John Wiley \& Sons, Inc.

Gershon, R. R. M., L. A. Magda, and A. N. Canton. 2010. Web-based weapons of mass destruction training for transit police. Journal of Public Transportation 13: 23-37.

Helmick, J. S. and D. Compton. 2004. The training factor (maritime and intermodal transportation security). Review of Business 25: 23-27.

Johnston, V. R. 2004. Terrorism and transportation policy and administration: Balancing the model and equations for optimal security. Review of Policy Research, 21: 263-274.

Kozub, C., M. Greenberg, C. Goldin, R. Noland, J. Carnegie, and R. Haider. 2009. Regional stakeholder meeting for New Jersey-New York-Philadelphia corridor. Report of CTSSR, New Brunswick, NJ.

Kozub, C., K. Lowrie, C. Goldin, and R. Haider. 2009b. Regional stakeholder meeting for Houston Metro Region. Report of CTSSR, New Brunswick, NJ.

Lammers, R. L., M. Davenport, F. Korley, S. Griswold-Theodorson, M. T. Fitch, A. T. Narang, L. V. Evans, A. Gross, E. Rodriguez, K. L. Dodge, C. J. Hamann, and W. C. Robey III. 2008. Teaching and assessing procedural skills using simulation: Metrics and methodology. Academic Emergency Medicine 28: 1079-1087.

Library of Congress. HR1, Sections 1408 (Public Transportation Security Training Program), 1517 (Railroad Security Training Program), and 1534 (Over-theRoad Bus Security Training Program), http: //thomas.loc.gov/cgi-bin/cpquery/ R?cp110: FLD010: @1\%28hr259\%29

Martin, H. J. 2010. Workplace climate and peer support as determinants of training transfer. Human Resource Development Quarterly 21: 87-104.

Meyer, M. D. 2008. The Nation's Transportation System as a Security Challenge. Wiley Handbook of Science and Technology for Homeland Security. 1-22.

Mitchell, C. S., M. L. Doyle, J.B. Moran, B. Lippy, J.T. Hughes, M. Lum and J. Agnew, J. 2004. Worker training for new threats: A proposed framework. American Journal of Industrial Medicine 46: 423-431. 
Myers, P. M., B. Watson, and M. Watson. 2008. Effective training programs using instructional systems design and e-learning. Process Safety Progress 27: 131138.

Ostroff, C. 1991. Training effectiveness measures and scoring schemes: A comparison. Personnel Psychology 44: 353-374.

President's Office, Surface Transportation Sub-IPC, Transborder Security Interagency Policy committee. 2010, Surface transportation security priority assessment. http: //www.whitehouse.gov/sites/default/files/rss_viewer/STSA.pdf

Shaw, J. 2010. Assessment of surface transportation security training needs: California statewide interviews. Report for CTSSR, New Brunswick, NJ.

Shaw, J., and K. Lowrie. 2010. Assessment of surface transportation security training needs: Union, trade association and training expert interviews. Report for CTSSR, New Brunswick, NJ.

Sitzman, T., B. S. Bell, K. Kraiger, and A.M. Kanar. 2009, A multilevel analysis of the effect of prompting self-regulation in technology-delivered instruction. Personnel Psychology 62: 697-734.

Steiner, D. D., G. H. Dobbins and W. A. Trahan. 1991. The Trainer-trainee interaction: An attributional model of training. Journal of Organizational Behavior 12: 271-286.

U.S. Department of Homeland Security. 2010. Quadrennial homeland security review report: A strategic framework for a secure homeland. http: //www.dhs. gov/xlibrary/assets/qhsr_report.pdf

U.S. Department of Homeland Security, Transportation Security Administration. TSA/FTA security and emergency management action items for transit agencies. http: //transit-safety.volpe.dot.gov/security/Securitylnitiatives/ActionItems/default.asp

U.S. Government Accountability Office. 2010. Intermodal transportation facilities, GAO-10-435R, memo from Charles Jezneck, May 27, 2010.

Van Der Klink, M., E. Gielen, and C. Nauta. 2001. Supervisory support as a major condition to enhance transfer. International Journal of Training and Development 5: 52-63.

Waugh, W. L. 2004. Securing mass transit: A challenge for homeland security. Review of Policy Research 21: 307-316. 
Young, D. R. W., and M. J. K. Findlater. 1972. Training and industrial relationsA broader perspective. Industrial Relations Journal 3: 3-22.

\section{About the Authors}

Karen W. Lowrie, Ph.D. (klowrie@rutgers.edu) is Associate Director of the Center for Transportation Safety, Security and Risk at Rutgers University, New Brunswick, New Jersey. She manages research projects related to transportation security and training, risk perception and environmental planning issues, has published dozens of peer-reviewed papers and serves as Managing Editor of Risk Analysis, an International Journal.

JUdY ShAw, PH.D. (judy.shaw@rutgers.edu) is a Senior Research Associate with the Center for Transportation Safety, Security and Risk at Rutgers. She is also an associate with the National Center for Neighborhood and Brownfields Redevelopment and manages projects associated with public awareness of security, school bus safety, community involvement, and water resource protection.

Michael R. Greenberg, Ph.D. (mrg@rutgers.edu) is Director of the Center for Transportation Safety, Security and Risk at Rutgers. He also directs the National Center for Neighborhood and Brownfields Redevelopment and is Associate Dean for Faculty at the Bloustein School of Planning and Public Policy. He is Editor-inChief of Risk Analysis, an International Journal and a Professor of Urban Planning with many awards of distinction and hundreds of publications. 